\title{
Mesiodistal sizes and intermaxillary tooth-size ratios of two populations; Spanish and Peruvian. A comparative study
}

\author{
Vanessa Paredes ${ }^{1}$, Freddie D. Williams ${ }^{2}$, Rosa Cibrian ${ }^{3}$, Freddie E. Williams ${ }^{4}$, Abraham Meneses ${ }^{5}$, Jose \\ Luis Gandia ${ }^{6}$
}

${ }^{1} \mathrm{PhD}$ in Odontology. MS in Orthodontics. Doctor Professor. Department of Orthodontics. Faculty of Medicine and Odontology, University of Valencia, Spain

${ }^{2} \mathrm{PhD}$ in Odontology. MS in Orthodontics. Professor Department of children and adolescent dentistry. Peruvian Odontology University Cayetano Heredia, Peru

${ }^{3}$ Titular Professor. Department of Physiology. Faculty of Medicine and Odontology, University of Valencia, Spain

${ }^{4}$ Director of Postgraduate Orthodontics Masters Course. Peruvian Odontology University Cayetano Heredia, Peru

${ }^{5}$ Director of the Department of children and adolescent dentistry. Peruvian Odontology University Cayetano Heredia, Peru

${ }^{6}$ Titular Professor. Director of Postgraduate Orthodontics Masters Course. Department of Orthodontics. Faculty of Medicine and Odontology, University of Valencia, Spain

Correspondence:

Av. Blasco Ibáñez 20-15

46010 Valencia. Spain

vanessa_paredes@yahoo.es

Received: 08/04/2010 Accepted: $24 / 04 / 2010$

\author{
Paredes V, Williams FD, Cibrian R, Williams FE, Meneses A, Gandia JL. \\ Mesiodistal sizes and intermaxillary tooth-size ratios of two populations; \\ Spanish and Peruvian. A comparative study. Med Oral Patol Oral Cir Bu- \\ cal. 2011 Jul 1;16 (4):e593-9. \\ http://www.medicinaoral.com/medoralfree01/v16i4/medoralv16i4p593.pdf

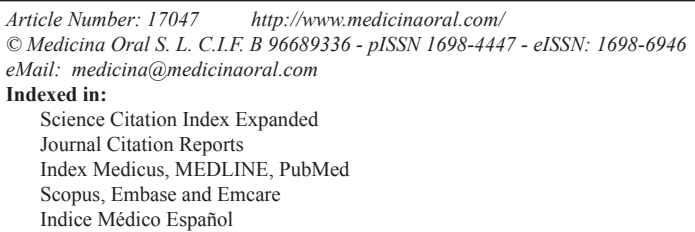

\begin{abstract}
Introduction: Adequate tooth-size ratios are required to ensure the satisfactory outcome of orthodontic treatment. Consequently, various methods of measuring tooth-size ratios have been developed being the Bolton ratio the most commonly accepted, known and used one. This ratio depending directly on mesiodistal tooth size has been associated with different ethnic backgrounds. Some authors suggest the need for specific standards for every population. Objectives: The objectives of our study were; to measure and to compare mesiodistal tooth sizes and the Anterior and Overall Bolton ratios in two different populations, one Peruvian and the other Spanish with the same digital method.

Material and Methods: The sample included 149 individuals composed of two groups; 99 Spanish (mean age 14.19), 65 being females and 34 males and 50 Peruvian (mean age 14.46), 18 being males and 32 females. The mesiodistal sizes of each of the patients were measured using a digital method and the Anterior and Overall Bolton ratios were calculated.

Results: Tooth size does indeed involve a strong ethnic component, and the Anterior Bolton ratio is specific for each ethnic group.

Conclusions: The conclusions are; tooth sizes of the Peruvian population were greater than those of the Spanish population. The Anterior Bolton ratio of Peruvian individuals was greater than that of the Spanish, whereas no differences were found for Overall Bolton ratio. These differences suggest the need for specific standards for the Spanish and Peruvian population.
\end{abstract}

Key words: Bolton ratio, Bolton index, mesiodistal tooth-size, populations. 


\section{Introduction}

Adequate tooth-size ratios are required to ensure the satisfactory outcome of orthodontic treatment. Consequently, various methods of measuring tooth-size ratios have been developed being the Bolton ratio (1) the most commonly accepted one. This ratio depending directly on mesiodistal tooth size have been associated with different ethnic backgrounds $(2,3)$ Some authors found differences in tooth sizes between ethnic groups (4-7) while others don't $(8,9)$. The only studies that figure in the literature on a Peruvian population $(10,11)$ found no difference in mesiodistal sizes when compared with a White population.

As regards the tooth size of the Spanish population, Ostos et al. (12) found that sizes were smaller than those of the American population, especially those of the black race. Sizes were more similar to the European population.

It is logical to expect that differences in mesiodistal tooth sizes can directly affect Bolton ratios. Some studies claim that the Bolton ratio cannot be applied to populations other than the White one, and that there is a need to individualise each population with their own ratios $(3,13-16)$ whilst others claim that it is indeed valid for other populations $(3,11,17)$.

There are only a few studies about tooth-size ratios on Peruvian or Spanish populations $(11,14)$. Paredes et al. (15) obtained anterior and overall Bolton ratios different to that of Bolton1 and showed that the Bolton ratio could not be applied to the Spanish population. Others concluded that although some statistically significant differences in tooth size were found between Peruvians compared with White standards, they were not likely to be clinically significant (11).

Given the controversy in the literature for the difference in tooth sizes between different ethnic groups, the aims of this study were to compare the mesiodistal tooth sizes in two different, but related populations, one Peruvian and the other Spanish and to calculate and compare the anterior and overall ratios of each of them with the same digital method.

\section{Materials and Methods}

The sample included 149 individuals and was composed of two groups. The first consisted of 99 Spanish adolescents residing in the city of Valencia, Spain, with a mean age of 14.19 SD 1.97, 65 being females and 34 males. All Spanish adolescents were Whites strictly of European decent. The second group was made up of 50 adolescent Peruvians in the city of Lima, Peru, 18 being males and 32 females. The mean age was 14.46 SD 3.38. Both groups were recruited from the Orthodontic Clinics in the Faculty of Odontology of the University of Valencia, Spain and the Peruvian University Cayetano Heredia, Peru, respectively. The three types of Angle molar class were present in both groups and none of them had previously received Orthodontic treatment. The material used in this study consisted of:

- Plaster casts of each person from the two population groups. All of them were made in the same way;

- A conventional scanner for digitalising all study models;

- Our own technology program, developed at the Faculty of Medicine and Odontology of the University of Valencia, Spain. The reliability and reproducibility of this program had already previously been tested and compared with traditional callipers (14). This program requires a digitalised image of what one wishes to measure and back-up software for undertaking measurements.

The inclusion criteria for the study models selected were:

- Presence of permanent dentition from first left-side molar to first right-side molar;

- Absence of alteration in the number of teeth;

- Absence of alteration in dental size and shape;

- Good quality of study models with good anatomic definition, both of soft and hard parts.

On each of the images obtained and calibrated, the points of mesial and distal occlusal contact, corresponding to the maximum mesiodistal size of each tooth, were marked, so automatically obtaining a line joining those points which shows the measurement taken. The software designed for this purpose determines dental sizes in millimeters from that data. The Anterior and Overall Bolton ratios were automatically determined. The digital method has a sensitivity of hundredths of a millimeter.

\section{Statistical method}

The values found were introduced into a database, so as to be processed using the statistical SPSS $\odot$ version v.11.5 for Windows package.

The Kolmogorov-Smirnov and Shapiro-Wilk test were applied to determine which measurements had normal distribution and, by doing so, to determine the type of statistics to be used. For statistical analysis, the samples of each ethnic group were grouped together per sex. The representative values of each group are represented as a mean \pm CI 95\% (Confidence Interval of 95\%).

The tooth size comparison between Spanish and Peruvian population was made by estimation of the difference between tooth sizes and its $95 \%$ confidence interval. Variance analysis with two variation factor (ethnic group and sex) was used to compare the groups using the post-hoc Bonferroni test in the Bolton study. The results were significant at the $95 \%$ confidence level. Mean differences were estimated to a confidence interval of 95\% (CI 95\%). The percentage of sexual dimorphism for mesiodistal tooth size was calculated. 


\section{Results}

Tooth sizes were found to be dependent both on sex and ethnicity to which they belonged. Hence, the sizes both of the Peruvian and Spanish populations are separated by sex and reflected in table 1. Left and right sizes were averaged for the analysis since the teeth were symmetric.

Table 2 shows the difference between the mesiodistal tooth sizes of Peruvians less those of the Spanish to confidence intervals of $95 \%$, both for males and females and for each tooth. Fig. 1 and 2 show these differences. The results for the Anterior and Overall Bolton ratios and confidence interval (CI) of $95 \%$, both for the Peruvian and the Spanish populations of our study, can be seen, expressed in percentages, in table 3 (in grey colour).

Mean anterior and overall tooth-size ratios between male

Table 1. Mesiodistal tooth-size of Peruvian and Spanish populations.

SD: standard deviation.

\begin{tabular}{|c|c|c|c|c|c|c|c|c|c|}
\hline & \multirow{3}{*}{ TEETH } & \multicolumn{4}{|c|}{ Peruvian } & \multicolumn{4}{|c|}{ Spanish } \\
\hline & & \multicolumn{2}{|c|}{ Men } & \multicolumn{2}{|c|}{ Women } & \multicolumn{2}{|c|}{ Men } & \multicolumn{2}{|c|}{ Women } \\
\hline & & Mean & SD & Mean & SD & Mean & SD & Mean & SD \\
\hline \multirow{6}{*}{$\begin{array}{c}\text { Upper } \\
\text { Arch }\end{array}$} & $1^{\text {st }}$ molar & 11.55 & 0.52 & 11.15 & 0.62 & 10.76 & 0.54 & 10.75 & 0.50 \\
\hline & $2^{\text {nd }}$ premolar & 7.80 & 0.35 & 7.67 & 0.40 & 7.09 & 0.45 & 6.97 & 0.36 \\
\hline & $1^{\text {st }}$ premolar & 7.95 & 0.34 & 7.88 & 0.47 & 7.38 & 0.42 & 7.37 & 0.41 \\
\hline & Canine & 8.62 & 0.42 & 8.42 & 0.49 & 8.07 & 0.42 & 8.09 & 0.45 \\
\hline & Lateral incisor & 7.62 & 0.49 & 7.60 & 0.57 & 7.05 & 0.70 & 7.07 & 0.47 \\
\hline & Central incisor & 9.16 & 0.50 & 8.96 & 0.50 & 8.86 & 0.57 & 8.98 & 0.51 \\
\hline \multirow{6}{*}{$\begin{array}{l}\text { Lower } \\
\text { Arch }\end{array}$} & $1^{\text {st }}$ molar & 12.35 & 0.52 & 11.79 & 0.65 & 11.49 & 0.70 & 11.36 & 0.56 \\
\hline & $2^{\text {nd }}$ premolar & 8.14 & 0.33 & 7.92 & 0,50 & 7.60 & 0.51 & 7.51 & 0.40 \\
\hline & $1^{\text {st }}$ premolar & 7.93 & 0.29 & 7.65 & 0.46 & 7.46 & 0.43 & 7.45 & 0.39 \\
\hline & Canine & 7.75 & 0.28 & 7.31 & 0.45 & 7.00 & 0.47 & 7.05 & 0.40 \\
\hline & Lateral incisor & 6.55 & 0.40 & 6.55 & 0.52 & 6.08 & 0.44 & 6.21 & 0.41 \\
\hline & Central incisor & 5.94 & 0.32 & 5.82 & 0.36 & 5.63 & 0.38 & 5.62 & 0.32 \\
\hline
\end{tabular}

Table 2. Differences in the means of upper and lower mesiodistal tooth-size between Peruvians and Spanish for each tooth and sex and the $95 \%$ confidence intervals (CI) of these differences. Values in grey colour mean that are not statistically significant.

\begin{tabular}{|c|c|c|c|c|c|c|}
\hline \multirow{3}{*}{$\begin{array}{c}\text { TEETH } \\
\text { UPPERARCH }\end{array}$} & \multicolumn{3}{|c|}{ MEN } & \multicolumn{3}{|c|}{ WOMEN } \\
\hline & \multirow[t]{2}{*}{ Dif P-S } & \multicolumn{2}{|c|}{ CI 95\% } & \multirow[t]{2}{*}{ Dif P-S } & \multicolumn{2}{|c|}{ CI 95\% } \\
\hline & & & & & & \\
\hline $1^{\text {st }}$ molar & 0.79 & 0.58 & 1.00 & 0.40 & 0.22 & 0.57 \\
\hline $2^{\text {nd }}$ premolar & 0.72 & 0.56 & 0.87 & 0.70 & 0.58 & 0.82 \\
\hline $1^{\text {st }}$ premolar & 0.57 & 0.42 & 0.72 & 0.51 & 0.37 & 0.64 \\
\hline Canine & 0.55 & 0.39 & 0.71 & 0.33 & 0.19 & 0.47 \\
\hline Lateral incisor & 0.57 & 0.34 & 0.80 & 0.53 & 0.37 & 0.69 \\
\hline Central incisor & 0.30 & 0.09 & 0.51 & -0.02 & -0.17 & 0.13 \\
\hline \multicolumn{7}{|l|}{ LOWERARCH } \\
\hline $1^{\text {st }}$ molar & 0.86 & 0.63 & 1.09 & 0.43 & 0.25 & 0.62 \\
\hline $2^{\text {nd }}$ premolar & 0.54 & 0.38 & 0.70 & 0.41 & 0.26 & 0.55 \\
\hline $1^{\text {st }}$ premolar & 0.48 & 0,34 & 0.61 & 0.20 & 0.07 & 0.33 \\
\hline Canine & 0.76 & 0.61 & 0.90 & 0.26 & 0.13 & 0.39 \\
\hline Lateral incisor & 0.47 & 0.30 & 0.63 & 0.34 & 0.19 & 0.48 \\
\hline Central incisor & 0.31 & 0.17 & 0.45 & 0.20 & 0.09 & 0.31 \\
\hline
\end{tabular}




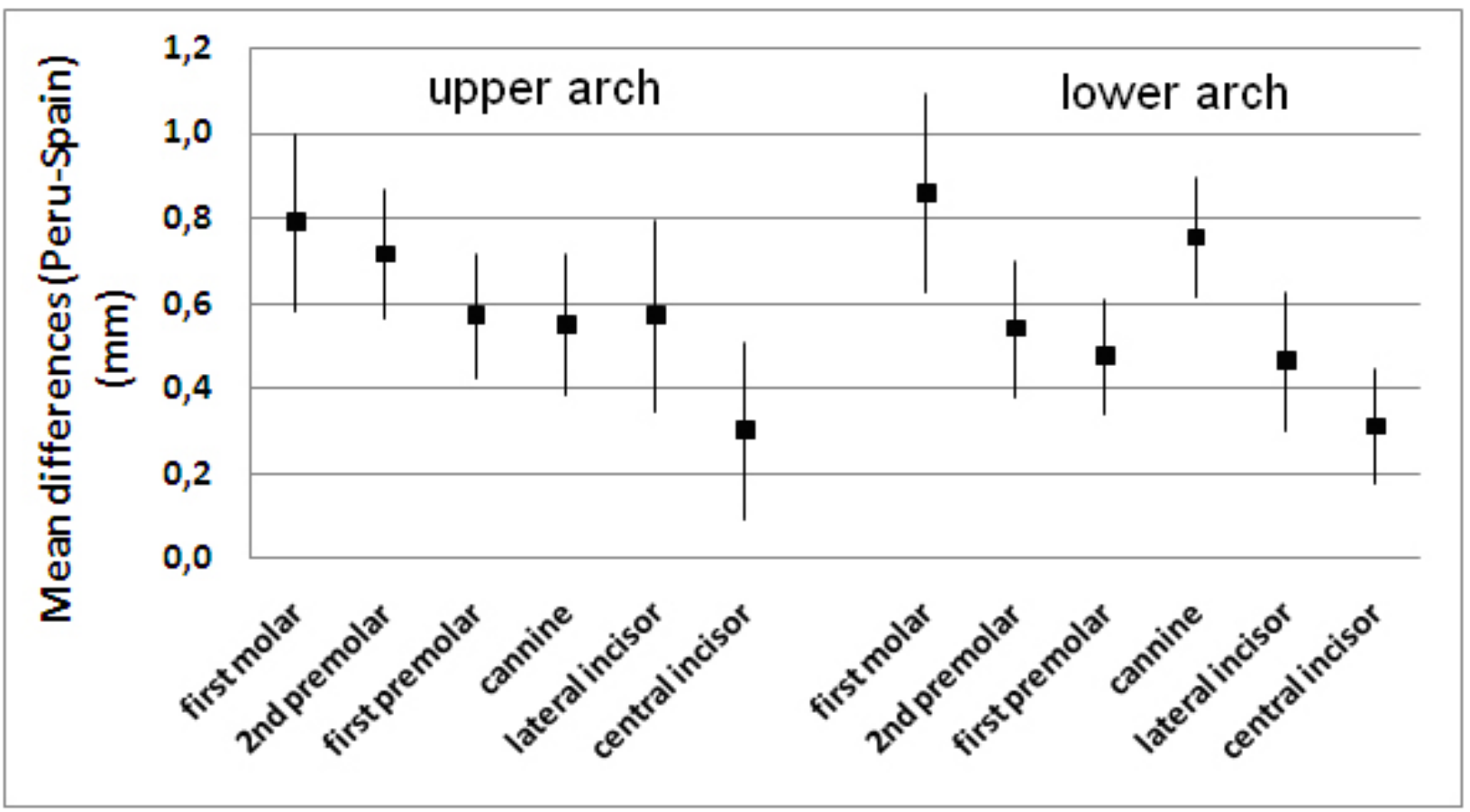

Fig. 1. Male differences in the means of mesiodistal tooth-size between Peruvians and Spanish for each tooth for the upper and lower arch.

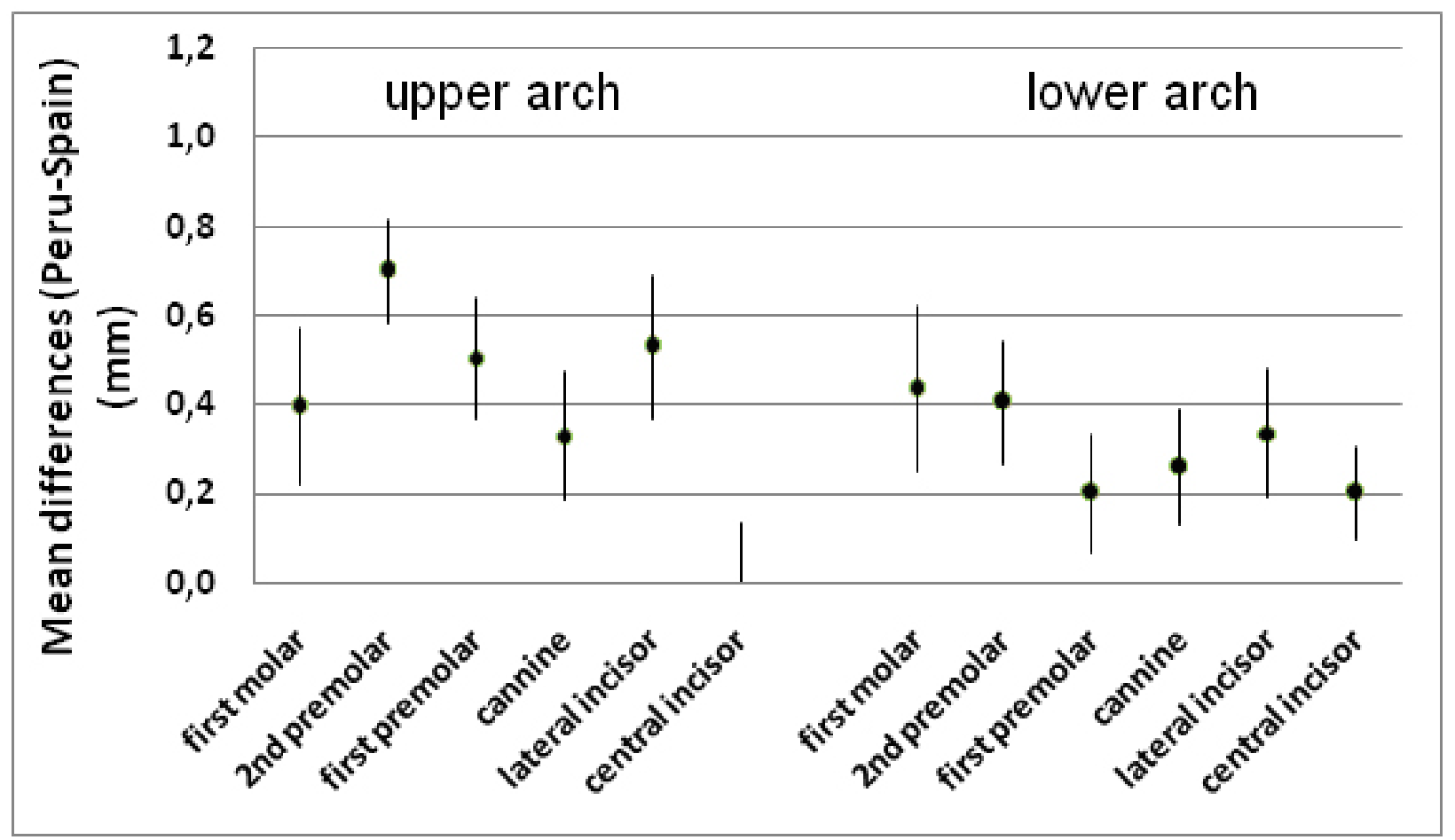

Fig. 2. Female differences in the means of mesiodistal tooth-size between Peruvians and Spanish for each tooth for the upper and lower arch. 
Table 3. Anterior and Overall Bolton ratios of different Peruvian and Spanish populations and our results. Statistically significant difference $\mathrm{a}>\mathrm{b}>\mathrm{c} \mathrm{p}<0.05$. Means are displayed with $95 \%$ Confidence Intervals (CI).

\begin{tabular}{|c|c|c|c|c|c|c|}
\hline & $\begin{array}{c}\text { ANTERIOR } \\
\text { BOLTON (\%) }\end{array}$ & $\begin{array}{c}\text { CI } 95 \% \\
\text { lower }\end{array}$ & $\begin{array}{c}\text { CI 95\% } \\
\text { upper }\end{array}$ & $\begin{array}{c}\text { OVERALL } \\
\text { BOLTON } \\
(\%)\end{array}$ & $\begin{array}{l}\text { CI } 95 \% \\
\text { lower }\end{array}$ & $\begin{array}{c}\text { CI 95\% } \\
\text { upper }\end{array}$ \\
\hline WAYNE BOLTON & $77.2^{\mathrm{c}}$ & 76.76 & 77.64 & $91.3^{\mathrm{b}}$ & 90.80 & 91.80 \\
\hline \multicolumn{7}{|c|}{ PERUVIANS } \\
\hline $\begin{array}{c}\text { PAREDES } \\
\text { WILLIAMS } \\
\text { (OUR STUDY) }\end{array}$ & $79.12^{b}$ & 78.37 & 79.87 & $91.51^{b}$ & 90.97 & 92.05 \\
\hline \multirow[t]{2}{*}{ BERNABE 11} & \multirow[t]{2}{*}{$78.09^{b}$} & \multirow[t]{2}{*}{77.72} & \multirow[t]{2}{*}{78.46} & $90.79^{b}$ & 90.45 & 91.13 \\
\hline & & & & $91.33^{b}$ & 90.92 & 91.74 \\
\hline $\begin{array}{c}\text { PAREDES } \\
\text { WILLIAMS } \\
\text { (OUR STUDY) }\end{array}$ & $78.32^{b}$ & 77.83 & 78.81 & $91.97^{\mathrm{b}}$ & 91.59 & 92.35 \\
\hline FERNANDEZ ${ }^{21}$ & $80.62^{\mathrm{a}}$ & 80.20 & 81.04 & $93.39^{\mathrm{a}}$ & 93.05 & 93.73 \\
\hline
\end{tabular}

and female samples are not statistically significantly in our study. Therefore, combined mean anterior and overall tooth-width ratios are presented; $78.32 \% \pm 2.45 \%$ / $91.97 \% \pm 1.95 \%$ and $79.12 \% \pm 2.70 \% / 91.51 \% \pm 1.95 \%$ for the anterior and overall tooth-width ratios for the Spanish population and for the Peruvian population, respectively.

Besides, (Table 3) shows the values of other, both Peruvian and Spanish, populations. Since Bernabe et al. (11) presents different values for the overall Bolton ratio for male and female in his study, we have considered both results separately in order to compare them.

\section{Discussion}

We believed it is interesting to compare the mesiodistal tooth sizes of two different but related populations* such as the Peruvian and the Spanish, as there are no comparative studies between them in the literature. *We have to bear in mind that Peru was s Spanish colony some centuries ago, so there was a great deal of mixture of the genes of Spanish White and the native Amerindian population of Colonial Peru.

The differences between the mesiodistal tooth sizes of Peruvians less those of the Spanish show that the teeth of Peruvians are larger than those of Spanish, all results being statistically significant, given that in all cases the confidence interval does not reach zero except for the maxillary central incisor for females, which appears with a negative value. For males, the tooth that presented the greatest difference in its mesiodistal tooth-size was the first molar, both maxillary and mandibular, followed by the mandibular canine, whilst the tooth that presented the least difference was the central incisor, both maxillary and mandibular. However, for females, the teeth with greatest difference were the maxillary second premolar, followed by the maxillary first premolar and lateral incisor. All teeth of the lower arch were those which presented the least differences.

Our results coincide with those of Bernabe et al. (11) who found differences between tooth-sizes of Peruvian and White populations, although these were not clinically significant for them.

Regarding the Anterior Bolton ratio, variance analysis shows that there is a difference for the Anterior Bolton ratio between Spanish and Peruvian subjects, without that difference being statistically significant, at the same time as both present a statistically significant difference with the Anterior ratio introduced by Bolton (1) the latter being lower. However, there are no statistically significant differences for the Overall Bolton ratio between the Peruvian and Spanish populations or with the standards of Bolton (1)

These results are very similar to other studies that compare the anterior and overall ratios of different populations such as White (13), Dominican (6), Syrian (17), Jordanian (18), Spanish (14), Iranian (19), Saudi (20) or Japanese (3) populations with Bolton's standards, as alterations occur mainly in the anterior ratio and not in the overall one (14-21).

The differences suggest the need for specific standards for the Spanish and Peruvian population. The reason for this finding might be the sample population or the ethnic groups and the fact that the population and gender composition of Bolton's sample was not specified and 
that it consisted of a very small sample (55 patients), which today would be unacceptable.

We also have to bear in mind that the Bolton sample was obtained from 55 models with excellent occlusion; 44 had received orthodontic treatment. In the Peruvian and Spanish sample all subjects were untreated and had malocclusions. Therefore, a direct statistical comparison between groups is disputable.

Furthermore, if we compare our results for the Bolton ratio with those of other Spanish populations, we can observe how our ratios are lower than those obtained by some Spanish authors (21) the results being statistically significant. The results of our study for the Bolton ratios for the Peruvian population are slightly higher to those obtained previously on Peruvian individuals (11), but this difference is not considered to be statistically significant, so they can be considered to be practically the same. If we compare all the results together, as shown in (Table 3), we see how the ratios we obtained for the Peruvian and Spanish populations are similar to those of Bernabe et al. (11) but not to either those of Bolton (1) or Fernández et al. (22). The values of Fernández et al. (22) are higher than those of our study, those of Bernabe et al. (11) and those of Bolton (1) which are lower than the others. This shows that values of the Bolton ratio vary not only between different populations, but also even within the same population.

Thus, the clinical relevance of this study is that the generalized use of the Bolton ratio and the proposed values for a harmonious dentition are questionable and might not be valid for other populations. The differences suggest the need for specific standards for the Spanish and Peruvian population.

\section{Conclusions}

1. Our hypothesis that there is no difference in the mesiodistal tooth sizes in two different but related populations were the same was not correct since mesiodistal tooth-sizes of the Peruvian population were greater than those of the Spanish population.

2. The teeth that presented the greatest differences in terms of size between the Peruvian and Spanish population were the maxillary and mandibular first molar and the mandibular canine in males and the first and second maxillary premolar and maxillary lateral incisor in females.

3. The relationships between the sizes of the mandibular and maxillary teeth are dependent on the population.

4. Mean anterior and overall tooth-width ratios between the male and female samples do not differ in a statically significantly way: Therefore, combined mean anterior and overall tooth-width ratios are presented; $78.32 \% \pm 2.45 \% / 91.97 \% \pm 1.95 \%$ and $79.12 \% \pm 2.70 \% /$ $91.51 \% \pm 1.95 \%$ for the anterior and overall tooth-width ratios for the Spanish population and for the Peruvian population, respectively.
5. The anterior ratio for the Peruvian sample is greater than the Spanish one, whilst there are no differences for the Overall Bolton ratio.

6. The anterior ratios for the Peruvian and Spanish samples are greater than Bolton's. The differences are statically significant and suggest the need for specific standards for Spanish and Peruvian populations.

\section{References}

1. Bolton WA. The clinical application of a tooth-size analysis. Am J Orthod. 1962; 48:504-29.

2. Buschang PH, Demirjian A, Cadotte L. Permanent mesiodistal tooth size of French-Canadians. J Can Dent Assoc. 1988;54:441-4.

3. Endo T, Shundo I, Abe R, Ishida K, Yoshino S, Shimooka S. Applicability of Bolton's tooth size ratios to a Japanese orthodontic population. Odontology. 2007;95:57-60.

4. Merz ML, Isaacson RJ, Germane N, Rubenstein LK. Tooth diameters and arch perimeters in a black and a white population. Am J Orthod Dentofacial Orthop. 1991;100:53-8.

5. Hattab FN, Al-Khateeb S, Sultan I. Mesiodistal crown diameters of permanent teeth in Jordanians. Arch Oral Biol. 1996;41:641-5.

6. Santoro M, Ayoub ME, Pardi VA, Cangialosi TJ. Mesiodistal crown dimensions and tooth size discrepancy of the permanent dentition of Dominican Americans. Angle Orthod. 2000;70:303-7.

7. Brook AH, Griffin RC, Townsend G, Levisianos Y, Russell J, Smith RN. Variability and patterning in permanent tooth size of four human ethnic groups. Arch Oral Biol. 2009;54 Suppl 1:S79-85.

8. Bishara SE, Fernandez Garcia A, Jakobsen JR, Fahl JA. Mesiodistal crown dimensions in Mexico and the United States. Angle Orthod. 1986;56:315-23.

9. Bishara SE, Jakobsen JR, Abdallah EM, Fernandez Garcia A. Comparisons of mesiodistal and buccolingual crown dimensions of the permanent teeth in three populations from Egypt, Mexico, and the United States. Am J Orthod Dentofacial Orthop. 1989;96:41622.

10. Bernabe E, Lagravère MO, Flores-Mir C. Permanent dentition mesiodistal and buccolingual crown diameters in a Peruvian sample. Int J Dent Anthropol. 2005;6:1-13.

11. Bernabé E, Major PW, Flores-Mir C. Tooth-width ratio discrepancies in a sample of Peruvian adolescents. Am J Orthod Dentofacial Orthop. 2004;125:361-5.

12. Ostos MJ, Travesi J, Gonzalez E. Análisis de los diámetros mesiodistales en dentición permanente. Ortod Esp. 1989;30:233-243.

13. Marin JM, Moreno JP, Barberia E, Alio JJ. Estudio de los diámetros mesiodistales de los dientes permanentes en una población de niños españoles. Ortod Esp. 1993;34: 219-232.

14. Smith SS, Buschang PH, Watanabe E. Interarch tooth size relationships of 3 populations: "does Bolton's analysis apply?". Am J Orthod Dentofacial Orthop. 2000;117:169-74.

15. Paredes V, Gandia JL, Cibrian R. Do Bolton's ratios apply to a Spanish population? Am J Orthod Dentofacial Orthop. 2006;129:42830.

16. Ta TA, Ling JY, Hägg U. Tooth-size discrepancies among different occlusion groups of southern Chinese children. Am J Orthod Dentofacial Orthop. 2001;120:556-8.

17. Uysal T, Sari Z. Intermaxillary tooth size discrepancy and mesiodistal crown dimensions for a Turkish population. Am J Orthod Dentofacial Orthop. 2005;128:226-30.

18. Nourallah AW, Splieth CH, Schwahn C, Khurdaji M. Standardizing interarch tooth-size harmony in a Syrian population. Angle Orthod. 2005;75:996-9.

19. Al-Khateeb SN, Abu Alhaija ES. Tooth size discrepancies and arch parameters among different malocclusions in a Jordanian sample. Angle Orthod. 2006;76:459-65.

20. Mirzakouchaki B, Shahrbaf S, Talebiyan R. Determining tooth size ratio in an Iranian-Azari population. J Contemp Dent Pract. 2007;8:86-93. 
21. Al-Tamimi T, Hashim HA. Bolton tooth-size ratio revisited. World J Orthod. 2005;6:289-95.

22. Fernandez Riveiro P, Suárez Quintanilla D, Otero Cepeda JL. Análisis odontométrico de una población maloclusiva: Índice de Bolton. Rev Esp Ortod. 1995; 25:119-126. 